\title{
EDITORIAL
}

\section{Creating testable questions in practical conservation: a process and 100 questions}

William J. Sutherland ${ }^{* 1,2}$, Jake M. Robinson ${ }^{3}$, David C. Aldridge ${ }^{4}$, Tim Alamenciak ${ }^{5}$, Matthew Armes ${ }^{6}$, Nina Baranduin ${ }^{7,8}$, Andrew J. Bladon ${ }^{1}$, Martin F. Breed ${ }^{9}$, Nicki Dyas ${ }^{10}$, Chris S. Elphick ${ }^{11}$, Richard A. Griffiths ${ }^{12}$, Jonny Hughes ${ }^{13}$, Beccy Middleton $^{14}$, Nick A. Littlewood ${ }^{15}$, Roger Mitchell ${ }^{16}$, William H. Morgan ${ }^{1}$, Roy Mosley ${ }^{10}$, Silviu O. Petrovan ${ }^{1}$, Kit Prendergast ${ }^{17}$, Euan G. Ritchie ${ }^{18}$, Hugh Raven ${ }^{19}$, Rebecca K. Smith ${ }^{1}$, Sarah H. Watts ${ }^{20,21}$ \& Ann Thornton ${ }^{1}$

*Corresponding author: w.sutherland@zoo.cam.ac.uk DOI: https://doi.org/10.52201/CEJ19XIFF2753

${ }^{1}$ Conservation Science Group, Department of Zoology, University of Cambridge, The David Attenborough Building, Pembroke Street, Cambridge CB2 3QZ, UK

${ }^{2}$ Biosecurity Research Initiative at St Catharine's (BioRISC), St Catharine's College, University of Cambridge, Cambridge CB2 1RL, UK

${ }^{3}$ Department of Landscape Architecture, University of Sheffield, The Arts Tower, Sheffield, S1O 2TN, UK

${ }^{4}$ Department of Zoology, University of Cambridge, Cambridge CB2 3QZ, UK

${ }^{5}$ Conservation and Restoration Ecology Lab, School of Environment, Resources and Sustainability, University of Waterloo, 200 University Ave., Waterloo, Ontario, Canada, N2L $3 G 1$

${ }^{6}$ Birmingham and Black Country Amphibian and Reptile Group, Centre of the Earth, 42 Norman Street, Birmingham, B18 $7 E P$, UK

7 Potwell Dyke Grasslands Action Group, Southwell Minster, Church Street, Southwell, Nottinghamshire, NG25 OHD, UK

${ }^{8}$ Sherwood Forest Trust, Unit 5, 6 Mansfield Rd, Edwinstowe, Mansfield NG21 9NJ, UK

${ }^{9}$ College of Science and Engineering, Flinders University, Bedford Park, SA 5042, Australia

${ }^{10}$ Sheffield and Rotherham Wildlife Trust, 37 Stafford Rd, Sheffield S2 2SF, UK

${ }^{11}$ Ecology \& Evolutionary Biology, University of Connecticut, Storrs, CT 06269, USA

${ }_{12}$ Durrell Institute of Conservation and Ecology, School of Anthropology and Conservation, Marlowe Building, University of Kent, Canterbury, CT2 7NR, UK

${ }^{13}$ UN Environment World Conservation Monitoring Centre, 219 Huntingdon Rd, Cambridge CB3 ODL, UK

${ }^{14}$ St Andrews Botanic Garden, Fife, KY16 8RT, UK

${ }_{15}$ SRUC (Scotland's Rural College), Craibstone Estate, Bucksburn, Aberdeen, AB21 9YA, UK

${ }^{16}$ Cambridge Conservation Forum, The David Attenborough Building, Pembroke Street, Cambridge CB2 3QZ, UK

17 West Coast Invertebrates Rescue and Rehoming, Kent St, Bentley, Western Australia, Australia, WA 6102

${ }^{18}$ School of Life and Environmental Sciences and Centre for Integrative Ecology, Deakin University, Burwood, Victoria, 3125 Australia

${ }^{19}$ Ardtornish, Morvern, Oban, Argyll, PA80 5UZ, UK

${ }^{20}$ Biological and Environmental Sciences, Faculty of Natural Sciences, University of Stirling, UK, FK9 4AL

${ }^{21}$ Corrour Estate, By Fort William, Inverness-shire, PH30 4AA, UK

\section{SUMMARY}

It is now clear that the routine embedding of experiments into conservation practice is essential for creating reasonably comprehensive evidence of the effectiveness of actions. However, an important barrier is the stage of identifying testable questions that are both useful but also realistic to carry out without a major research project. We identified approaches for generating such suitable questions. A team of 24 participants crowdsourced suggestions, resulting in a list of a hundred possible tests of actions.

\section{BACKGROUND}

There is a dearth of tests of the effectiveness of actions in many areas of practical conservation (Christie et al. 2021). The most realistic means of reducing this problem is testing of actions by researchers and practitioners (Sutherland et al. 2013). The Conservation Evidence Journal was established to help fill this gap. Such small-scale experiments are fundamental to effective conservation practice. By testing relatively minor variations in methods, (such as whether partially buried logs are better for biodiversity than exposed logs), or challenging the accepted 'norm', (for example, does covering a coppiced stool with brash encourage greater re-growth compared to a stool left uncovered?), will increase the evidence base, so increasing confidence in using the most effective methods and enable concentrating resources appropriately.

Practitioners have also reported a lack of skills in evaluating evidence and critical thinking (Downey et al. 2021). Ockendon et al. (2021) identifies barriers to testing, especially the challenge of identifying suitable experimental designs, and offers guidance on overcoming them. From these studies it became apparent that a key issue was identifying suitable questions that are realistic to test. We thus collectively established suggested processes and a hundred examples. Such small-scale, practical, and easily replicated experiments could substantially add to the evidence-base for biodiversity conservation. 
We fully accept that ideas that are testable by simple comparisons will not deal with some major areas, such as testing policies or landscape-scale interventions. Previous exercises have identified those larger questions that could be answered by a research programme (e.g. $\mathrm{Zu}$ Ermgassen et al. 2020, Izurieta et al. 2018, Ockendon et al. 2018, Green et al. 2017).

Unlike projects underpinned by a research programme, here we considered how to identify smallscale, easily testable, low-cost experiments. We suggested a maximum of one month total time for establishing the experiments and collecting the data.

In 2021, Ockendon et al. identified several barriers to the effective integration of experiments into conservation management and suggested ways to overcome these. One way forward was identifying opportunities to add simple experiments into practical operations. These, Ockendon et al. (2021) suggested, could be i) results needed to inform management; ii) relevant skills accessible; and iii) management plans amenable to including an experiment. Using these as the basis of a 'toolkit' for practitioners to use evidence-based conservation, we can identify where there are gaps in our knowledge on how to find, test, and interpret the evidence. In addition, Downey et al. (2021) identified five key elements required in the teaching of evidence-based conservation: Ask, Access, Appraise, Apply, Audit. The first step, Ask (identifying the problem and formulating a focused question), is the target of this paper.

The purpose of this exercise is to explore the practicality of processes for identifying questions. The list of 100 questions given should be considered as examples rather than an agreed priority, but we also hope that it encourages some to attempt to test some these questions.

\section{ACTIONS}

\section{Four options for identifying suitable questions}

I. Take statements provided, such as from guidance. Then ask whether it seems to be supported by evidence. If not, whether it is sufficiently important and practical to test using a simple experiment.

II. Start with the problem, then consider the range of possible solutions and look for evidence to support or refute the proposed action. Then consider the evidence gaps and, if there are gaps, consider whether they would be good subjects for tests.

III. Consider whether a process can be improved. For example the importance of dead wood is well accepted (e.g. Ulyshen 2016) yet, despite the existence of hundreds of studies, there are few that examine the practical means of achieving this, such as the consequences on invertebrate biodiversity of providing dead wood logs singly or in piles; partly buried or left on the surface; in sunlight or shade; drilled or distressed to increase the surface or which species of tree to retain as dead wood if removing some.

IV. Consider a change that is taking place, such as the creation of a meadow. Can this be done in an experimental manner?

Using the process outlined in Figure 1, we sought ideas for questions from members of the Conservation Evidence team. We then actively sought wider global involvement by asking for suggestions by crowd sourcing including through Twitter and a range of contacts. We acknowledge that this may have resulted in a bias towards those working in developed countries, however we hope that this would have been mitigated to an extent as our initial contacts shared the message.
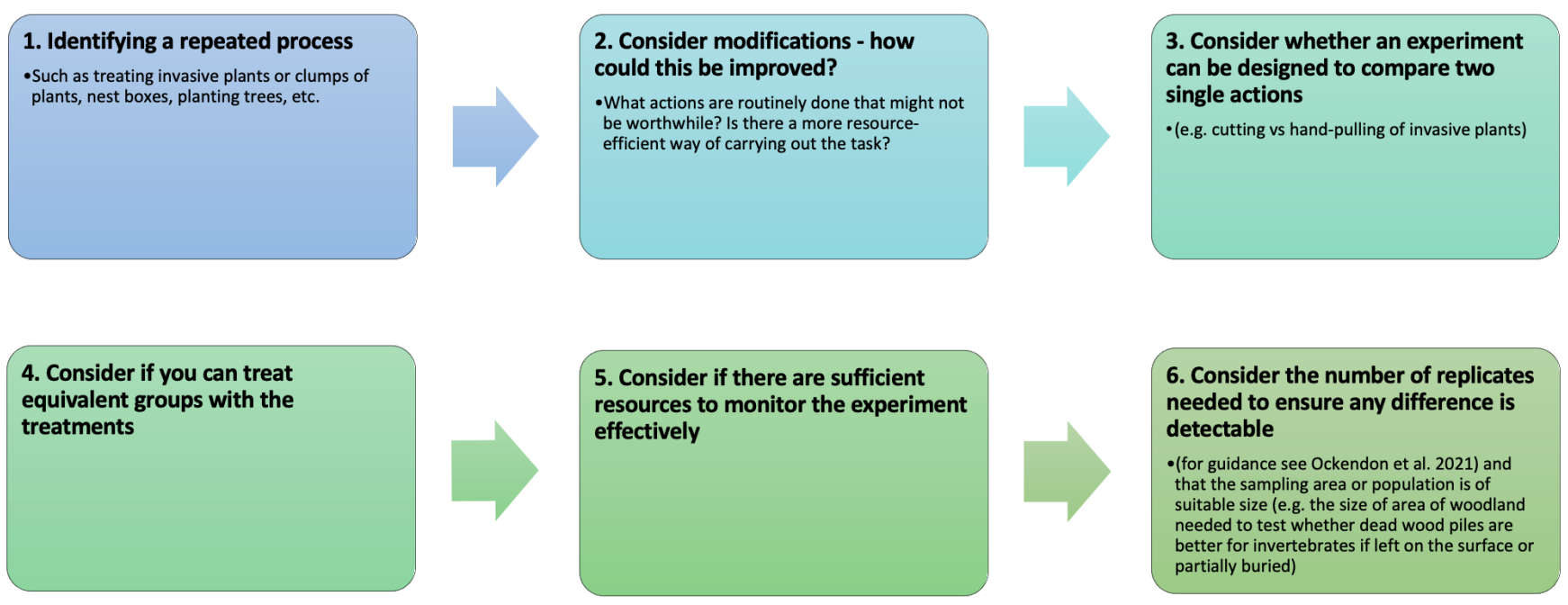
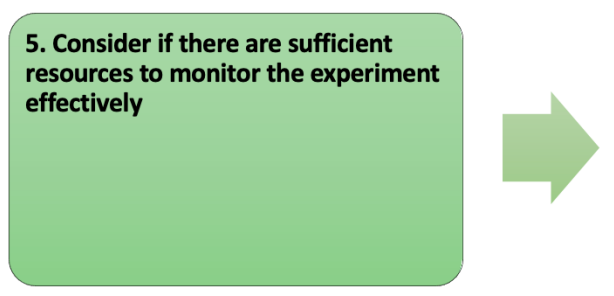

Figure 1: Step-wise process for creating a suitable question 
We set five main criteria for a question:

I. Answers a question about the effectiveness of conservation actions that is of interest to practitioners.

II. The action is not already well tested.

III. Specific, measurable actions so not How do you encourage wider community engagement in the reserve? but Does providing snacks increase the chance that a volunteer returns to volunteer again? Questions work best as a comparison between two different actions (e.g. action A vs action B) rather than action vs no action. Practitioners can determine whether there is any meaningful difference between actions and, therefore, costeffective to implement (Sutherland et al. 2013).

IV. Can realistically lead to well-designed experiments (i.e. with control or comparator) allowing multiple $(10+)$ replicates. In looking for options that are likely to have a reasonable sample size we found it useful to consider topics where it is easy to have multiple replicates, such as nest boxes, invasive plants, tree planting, or teaching sessions to visiting groups. It was also useful to consider opportunities to create replicate patches, such as grassland restoration or agricultural management.

V. Questions that could be answered by between a couple of days and a month of field work. That time includes both the setting out of the experiment and the collection of data (which may be months or years later). Potential projects could be run by land managers or by researchers, such as students, but these would usually have to be of short duration. Some may require equipment or specialised skills and all need to be in line with legislation.

\section{CONSEQUENCES}

\section{The list of questions}

Responses and suggestions for questions were added to a Google Doc. Questions were assessed by the lead authors to ensure they fulfilled the criteria for inclusion. Those who suggested at least one suitable question were invited to be authors.

We have categorised the questions using five overarching themes: invasive and problem species; habitat creation; habitat management; infrastructure; and working with others. These are presented as suggestions for experiments and are not intended to be viewed as the most important questions facing biodiversity conservation but as contributing to the evidence-base for effective actions. If the experimental opportunities are not immediately obvious then clarification is given in italics.

\section{Invasive and problem species}

1. Are chemical treatments more efficient than cutting or rolling, for example for bracken control?

2. How does stem injection of herbicide compare with spraying on leaves for killing a specified invasive plant species?

3. Does reseeding with native species after removing invasive plants reduce the rate of regrowth?

4. Can the inoculation of allelochemical-degrading bacteria help to suppress the re-sprouting capacity of invasive species, such as Fallopia japonica?

5. Does spraying of invasive plants with herbicide subsequently reduce the recruitment of native plant species?

6. Does topsoil removal reduce the invasive seed bank, and does the cleared area present a soil matrix more conducive to planting native species than the topsoil?

7. Is the removal of plant cover by heat, electric shock or chemical treatment more conducive to establishing native species (e.g. a meadow) than turf /topsoil removal?

8. How do established methods for controlling invasive plants (e.g. chemical, mechanical, hot water, burning) affect soil microbiomes and/or fungal communities?

9. Does the use of vole guards promote survival and growth of planted upland trees?

10. Do sprays made of emulsified animal fat deter browsing of upland trees by large herbivores?

11. Does covering seedling upland native trees with brash prevent grazing by deer and other animals?

12. Does a fibrous barrier made of unwashed sheep's wool deter browsing of tree seedlings by small mammals?

13. Can a barrier of felled trees and/or brash be used to deter large herbivores from an area in a forest as effectively as fencing?

14. Does adding copper rings around the base of the plants reduce mollusc grazing?

15. Does removal of macro-algal mats (e.g. Ulva spp.) increase benthic invertebrate diversity in intertidal mudflats?

16. Does clearance of macro-algal mats from intertidal mudflats prevent or reduce regrowth the following year?

17. Can repeated trapping and removal help to reduce invasive crayfish populations?

18. Does removal of feral honeybee colonies in parks lead to increased native insect visits? 


\section{Habitat creation}

19. Are logs or branches left for invertebrates better in piles or individually?

20. Are logs better for biodiversity if partly buried?

21. Can cut logs left for biodiversity be improved by creating a rough surface or cutting/drilling to enlarge surface area?

22. Does pushing down trees (i.e. to break or uproot them) rather than felling (i.e. neat cut with a chainsaw) attract a greater diversity of invertebrates?

23. Does creating pools in cut stumps benefit invertebrate biodiversity?

24. Does the benefit to amphibians of fallen or cut logs on the forest floor depend on the presence or absence of leaf litter?

25. Does the benefit to amphibians of fallen or cut logs on the forest floor increase depending on exposure or slope (or other factors that might influence humidity)?

26. Is there a difference in the effects on insects between raking and use of a leaf-blower when clearing leaves?

27. Does the use by invertebrates of bare scrapes created in grassland vary according to slope direction?

28. Is light scarification combined with scattering of woodland brash/leaf litter effective in restoring soils and allowing natural regeneration in long deforested upland acid habitats?

29. Do leaky dams influence the abundance/richness/diversity of invertebrates?

30. Does the use of geotextiles and cut vegetation, such as heather brash, promote revegetation of upland eroded bare peat, Sphagnum moss colonisation and peat formation?

31. Does "lasagna gardening" (putting down layers of straw, cardboard and compost and then planting into that) reduce weeds and result in greater tree growth?

32. Does heather cutting, as part of bog restoration, aid re-establishment of peat-forming Sphagnum mosses?

33. Can planting of bog sedges, such as cottongrass Eriophorum, promote colonisation of Sphagnum moss on upland eroded bare peat?

34. Does inoculation with root fragments containing mycorrhizal fungi promote the growth and survival of planted upland trees?

35. Does adding biochar to holes when planting trees improve tree survival or growth?

36. What type of soil disturbance (raking, digging, animal trampling, mechanical cultivation etc. is best to promote the germination of buried seed?
37. Does sowing seeds/planting native vegetation on roadside verges increase the abundance of invertebrates and invertebrate species?

38. Does reducing vegetation cover on existing rock piles affect the abundance of invertebrates?

39. Does creating refuges in ponds increase numbers of breeding amphibians?

40. Is there a benefit to water voles of installing buffer strips along water courses?

41. Does providing water sources, such as cattle troughs or spring boxes, increase bat activity in arid landscapes?

42. What is the best time to move plants with bulbs when flowering or dormant?

43. Does planting flowers in large clumps increase native bee visits over planting flowers in a mix?

44. Is there a difference in the abundance/richness of invertebrates in attenuation ponds (waterbodies designed to drain away after flood storage) versus typical ponds that hold water year-round?

45. Is aquatic biodiversity in newly created ponds influenced by the provision of terrestrial habitat features such as log piles and hibernacula?

46. For newly created ponds, is there a significant difference between artificially planted vs naturally developing vegetation with regards to attracting aquatic biodiversity in the initial colonisation phase?

47. Can translocated Sphagnum be used to restore peat-forming mosses to newly created bog pools during peatland restoration?

48. Does the depth of newly created bog pools influence the species composition of colonising invertebrates during peatland restoration?

49. What is the growth rate, and survival of trees in recyclable tubes compared with plastic tubes and over what period does the tube disintegrate?

50. Does inoculation with fragments of fungal sporocarps increase growth and survival of tree seedlings (for example Hebeloma inoculation of Oak)?

51. Does the use of fertiliser in tree nursery compost reduce colonisation of tree seedlings by mycorrhizal fungi?

52. What is the success rate of translocating epiphytic lichens to new host trees using different methods such as stapling or gluing? 


\section{Habitat management}

53. Does covering the 'stool' of coppiced trees with brash improve regrowth?

54. Are brash piles (quick) or woven brash barriers (time consuming) more effective at encouraging regrowth of coppiced trees?

55. Is there a significant difference in sapling success and early growth rate in human-assisted vs naturally dispersed/planted tree seeds? Use natural regeneration chronosequence over a year and compare with human-planted seeds in other plots.

56. Do plant ecotypes establish better when planted into soil that is inoculated with their local vs. nonlocal microbiota?

57. Does not raking leaves result in more insects in a lawn?

58. Does not raking leaves increase the diversity of plants in a lawn?

59. Does not mulching and leaving patches of bare ground in gardens increase ground-nesting bees in an area?

60. How many invertebrates persist after grass is cut by scythe, strimmer or lawnmower?

61. Does daily watering of flowers in summer increase insect visits? Hypothesis that this will allow plants to produce nectar and not dry out.

62. Does the type of material (wood vs plastic, or different types of wood) affect the use of bee tubes? Is this species dependent?

63. Do plastic tree guards reduce invertebrate diversity and/ or abundance within the area? Compare sites with and without tree guards (could compare other materials too).

64. Does leaving dandelions to grow and flower on garden lawns (rather than weeding them) promote invertebrate and bird diversity?

65. Does cutting vegetation along road verges (to increase visibility for motorists) reduce numbers of dead mammals on roads?

66. Is animal grazing or mechanical cutting better for promoting targeted heathland biodiversity (e.g. sand lizards)?

67. Does providing refuges after prescribed burns increase the rate of recolonisation by small mammals?

68. Does providing refuges after heathland wildfires help reestablish reptile populations?

69. Do modified gully pots/kerbs reduce amphibian mortality in gully pots?

70. Do warning signs e.g. for crossing amphibians reduce the speed and care of motorists?

71. Does removing tree canopy increase breeding amphibians in ponds?

72. Does bat activity increase if lighting is directed away from bat access points or habitat?
73. Does bat (and insect) activity decrease if UV filters are used on lights? Can also test 'warm' white LED against 'cool' LED lights

74. Can UV lights be used to improve foraging conditions for bats prior to hibernation by creating artificial prey patches by attracting insect prey and increasing foraging activity by bats?

\section{Infrastructure such as nest boxes}

75. Does putting bird nest boxes up in pairs increase occupancy by less competitive species?

76. Are "swift bricks" at least as successful as other nesting sites for successful breeding events?

77. Does using wood/species from the local environment to make nest boxes (for birds/bats) influence nesting behaviour and/or increase nesting uptake/success? Needs to be compared with woodcrete boxes etc.

78. Does putting up bat boxes facing in different directions increase usage compared to boxes facing the same direction?

79. Does inoculation of nest boxes from external sources with materials from the local environment (such as rubbing with local soil, lichen etc.) increase nesting uptake/success?

80. Does regular cleaning increase bat box occupancy?

81. Does treating bird boxes with boiling water reduce parasite infestations?

82. Does providing cleaned bird nest boxes with hay increase use?

83. What is the impact of cleaning bird feeders on bacterial levels over time? Can also compare different cleaning methods.

84. How does bird feeder design and/or food type affect consumption rate?

85. Does the type of material (wood vs plastic, or different types of wood) affect the use of bee tubes? Is this species dependent?

86. Does the colour around a bee tube (i.e. painted blue vs. left natural) influence occupancy?

87. How does the placing of bee hotels, such as proximity to buildings, influence nest occupancy of bee hotels?

88. Does low intensity lighting reduce attraction of invertebrates?

89. Do 'warm white' (rather than 'cool') LED lights reduce attraction of invertebrates?

90. Does red light reduce attraction of invertebrates? 


\section{Working with others}

91. Does providing snacks increase the chance that a volunteer returns to volunteer again? There are a host of other possible experiments (explaining importance, buddy scheme etc.)

92. Does an educational element (e.g., learning about ecology) during conservation volunteering activities increase volunteer satisfaction and return rate?

93. Does tailored individual feedback increase volunteer engagement with biological recording?

94. Does changing the way a volunteer work party is structured (alone, in pairs, in a group) affect the amount of work done?

95. Will follow-up information on the success of a project sent to volunteers increase the chance that they will volunteer again?

96. Are people more likely to volunteer if they have previously volunteered? Comparator groups volunteered vs. non-volunteered.

97. Are volunteers more satisfied and more likely to return if they work with people of the same demographic (i.e. groups of retirees, groups of teens) rather than mixed-age groups?

98. Does training increase the probability that arborists and forestry operatives identify potential bat roost features and signs?

99. Does the duration of citizen science projects affect whether they are completed? For example, give different designs to different schools.

100. Does stating you will end your teaching session with a quiz with a prize increase information retention? This needs to have replicates, such as a visitor centre or field study centre teaching the same material to repeated groups. Ideally allow for the time the quiz takes up (so short talk $v$ short talk with quiz v longer talk). The speaker should be unaware of which topics are in the quiz but have a list of facts to cover.

\section{DISCUSSION}

Moving forward, this process might be useful for groups, such as those working on specific problems or for an organisation, to create their own list. Groups may also wish to rank such questions to identify research priorities.

Anyone wanting to develop their own list could apply the well-established P.I.C.O. model as a framework to help identify well designed, testable, questions (Richardson et al. 1995). P.I.C.O. comprises Population (e.g. planted upland trees), Intervention (inoculation with root fragments containing mycorrhizal fungi), Comparison (control without inoculation or inoculation at a different growth stage) and Outcome (tree growth and survival). This can also be modified to P.I.C.O.T. by including Time (period over which the action will be studied).

In developing this process and list of questions, we were surprised at just how many simple questions remain unanswered. These are often the sort of actions carried out by practitioners on a regular basis. Perhaps if organisations or individuals tested a couple of actions each year, and reported their findings, we could significantly improve outcomes for conservation by carrying out those actions that work rather than actions that don't work.

\section{ACKNOWLEDGEMENTS}

This work is funded by Arcadia, MAVA and the David and Claudia Harding Foundation.

\section{REFERENCES}

Christie, A.P., Amano, T., Martin, P.A., Petrovan, S.O., Shackelford, G.E., Simmons, B.I., Smith, R.K., Williams, D.R., Wordley, C.F.R. and Sutherland, W.J. 2021. The challenge of biased evidence in conservation. Conservation Biology, 35, 249-262. https://doi.org/10.1111/cobi.13577

Downey, H., Amano, T., Cadotte, M., Cook, C.N., Cooke, S.J., Haddaway, N.R., Jones, J.P.G., Littlewood, N., Walsh, J.C., Abrahams, M.I., Adum, G., Akasaka, M., Alves, J.A., Antwis, R.E., Arellano, E.C., Axmacher, J., Barclay, H., Batty, L., Benítez-López, A., Bennett, J.R. Berg, M.J., Bertolino, S., Biggs, D., Bolam, F.C., Bray, T., Brook, B.W., Bull, J.W., Burivalova, Z., Cabeza, M., Chauvenet, A.L.M., Christie, A.P., Cole, L., Cotton, A.J., Cotton, S., Cousins, S.A.O., Craven, D., Cresswell, W., Cusack, J.J., Dalrymple, S.E., Davies, Z.G., Diaz, A., Dodd, J.A., Felton, A., Fleishman, E., Gardner, C.J., Garside, R., Ghoddousi, A., Gilroy, J.J., Gill, D.A., Gill, J.A., Glew, L., Grainger, M.J., Grass, A.A., Greshon, S., Gundry, J., Hart, T., Hopkins, C.R., Howe, C., Johnson, A., Jones, K.W., Jordan, N.R., Kadoya, T., Kerhoas, D., Koricheva, J., Lee, T.M., Lengyel, S., Livingstone, S.W., Lyons, A., McCabe, G., Millett, J., Montes Strevens, C., Moolna, A., Mossman, H.L., Mukherjee, N., Muñoz-Sáez, A., Negrões, N., Norfolk, O., Osawa, T., Papworth, S., Park, K.J., Pellet, J., Phillott, A.D., Plotnik, J.M., Priatna, D., Ramos, A.G., Randall, N., Richards, R.M., Ritchie, E.G., Roberts, D.L., Rocha, R., Rodríguez, J.P., Sanderson, R., Sasaki, T., Savilaakso, S., Sayer, C., Sekercioglu, C., Senzaki, M., Smith, G., Smith, R.J., Soga, M., Soulsbury, C.D., Steer, M.D., Stewart, G., Strange, E.F., Suggitt, A.J., Thompson, R.R.J., Thompson, S., Thornhill, I., Trevelyan, R.J., Usieta, H.O., Venter, O., Webber, A.D., White, R.L., Whittingham, M.J., Wilby, A., Yarnell, R.W., ZamoraGutierrez, V., \& Sutherland, W.J. (2021) Training future generations to deliver evidence-based 
conservation and ecosystem management. Ecol. Solut. Evidence, 2, e12032. https://doi.org/10.1002/2688-8319.12032

Green, J.M.H., Cranston, G.R., Sutherland, W.J., Tranter, H.R., Bell, S.J., Benton, T.G., Blixt, E., Bowe, C., Broadley, S., Brown, A., Brown, C., Burns, N., Butler, D., Collins, H., Crowley, H., DeKoszmovszky, J., Firbank, L.G., Fulford, B., Gardner, T.A., Hails, R.S., Halvorson, S., Jack, M., Kerrison, B., Koh, L.S.C., Lang, S.C., McKenzie, E.J., Monsivais, P., O’Riordan, T., Osborn, J., Oswald, S., Price Thomas, E., Raffaelli, D., Reyers, B., Srai, J.S., Strassburg, B.B.N., Webster, D., Welters, R., Whiteman, G., Wilsdon, J. \& Vira, B. 2017. Research priorities for managing the impacts and dependencies of business upon food, energy, water and the environment. Sustainability Science, 12, 319-331.

https://doi.org/10.1007/s11625-016-0402-4

Izurieta, A., Delgado, B., Moity, N., Calvopiña, M., Cedeño, I., Banda-Cruz, G., Cruz, E., Aguas, M., Arroba, F., Astudillo, I., Bazurto, D., Soria, M., Banks, S., Bayas, S., Belli, S., Bermúdez, R., Boelling, N., Bolaños, J., Borbor, M., Brito Ma., L., Bucheli, L., Campbell, K., Carranza, D., Carrión, J., Casafont, M., Castro, X., Chamorro, S., Chávez, J., Chicaiza, D., Chumbi, R., Couenberg, P., Cousseau, D., Cruz, M., d'Ozouville, N., de la Guía, C., de la Torre, G., Díaz, C.M., Duchicela, J., Endara, D., Garcia, V., Gellibert, C., Gibbs, J., Guzmán, J.C., Heylings, P., Iglesias, A., Izurieta, J.C., Jaramillo, P., Klingman, A., Laurie, A., Leon, P., Medina, J., Mendieta, E., Merlen, G., Montalvo, C., Naula, E., Páez-Rosas, D., Peralta, M., Peralvo, M., Piu, M., Poma, J., Pontón, J., Pozo, M., Proaño, D., Ramos, M., Rousseaud, A., Rueda, D., Salinas, P., Salmoral, G., Saraguro, S., Simón-Baile, D., Tapia, W., Teran, B., Valverde, M., Vargas, A., Vega, J., Velásquez, W., Vélez, A., Verdesoto, S., Villarraga, H.G., Vissioli, F., Viteri-Mejía, C., Norris-Crespo, L., Cooke, S.C., Toral-Granda, M.V., Sutherland, W.J. (2018) A collaboratively derived environmental research agenda for Galápagos. Pacific Conservation Biology, 24, 168-177. https://doi.org/10.1071/PC17053
Ockendon, N., Amano, T., Cadotte, M., Downey, H., Hancock, M. H., Thornton, A., Tinsley-Marshall, P., \& Sutherland, W. J. (2021) Effectively integrating experiments into conservation practice. Ecol. Solut. Evidence, 2, e12069. https://doi.org/10.1002/2688-8319.12069

Ockendon, N., Thomas, D.H.L., Cortina, J., Adams, W.M., Aykroyd, T., Barov, B., Boitani, L., Bonn, A., Branquinho, C., Brombacher, M., Burrell, C., Carver, S., Crick, H.Q.P., Duguy, B., Everett, S., Fokkens, B., Fullers, R.J., Gibbons, D.W., Gokhelashvili, R., Griffin, C., Halley, D.J., Hotham, P., Hughes, F.M.R., Karamanlidis, A.A., McOwen, C.J., Miles, L., Mitchell, R., Rands, M.R.W., Roberts, J., Sandom, C.J., Spencer, J.W., ten Broeke, E., Tew, E.R., Thomas, C.D., Timoshyna, A.A., Unsworth, R.K.F., Warrington, S. \& Sutherland, W.J. 2018. One hundred priority questions for landscape restoration in Europe. Biological Conservation, 221, 198-208. https://doi.org/10.1016/j.biocon.2018.03.002

Richardson, W.S., Wilson, M.C., Nishikawa, J. \& Hayward, R.S. (1995) The well-built clinical question: a key to evidence-based decisions. ACP J Club 123, A12-3.

Sutherland, W.J., Mitchell, R., Walsh, J., Amano, T., Ausden, M., Beebee, T.J.C.,Bullock, D., Daniels, M., Deutsch, J., Griffiths, R.A., Prior, S.V., Whitten, T. \& Dicks, L.V. (2013) Conservation practice could benefit from routine testing and publication of management outcomes. Conserv. Evid. Jour. 10, 1-3.

Ulyshen, M.D. (2016) Wood decomposition as influenced by invertebrates Biol. Rev., 91, $70-85$. https://doi.org/10.1111/brv.12158

Zu Ermgassen, P.S.E., Bonačić, K., Boudry, P., Bromley, C.A., Cameron, T.C., Colsoul, B., Coolen, J.W.P., Frankić, A., Hancock, B., van der Have, T.M., Holbrook, Z., Kamermans, P., Laugen, A.T., Nevejan, N., Pogoda, B., Pouvreau, S., Preston, J., Ranger, C.J., Sanderson, W.G., Sas, H., Strand, A. \& Sutherland, W.J. 2020. Forty questions of importance to the policy and practice of native oyster reef restoration in Europe Aquatic Conservation, 30, 2038-2049. https://doi.org/10.1002/aqc.3462

The Conservation Evidence Journal is an open access online journal devoted to publishing the evidence on the effectiveness of management interventions. The other papers from The Conservation Evidence Journal are available from www.conservationevidencejournal.com. The pdf is free to circulate or add to other websites and is licensed under the Creative Commons Attribution 4.0 International License http://creativecommons.org/licenses/by/4.0/. Under this licence, authors retain ownership of the copyright for their articles. 